\title{
Estimating the Economic Impact of Breeding Nonspecific Resistance to Leaf Rust in Modern Bread Wheats
}

\author{
M. Smale, R. P. Singh, K. Sayre, P. Pingali, S. Rajaram, and H. J. Dubin, International Maize and Wheat Im- \\ provement Center, Lisboa 27, Apartado Postal 6-641, Mexico, D.F., 06600, Mexico
}

\begin{abstract}
Smale, M., Singh, R. P., Sayre, K., Pingali, P., Rajaram, S., and Dubin, H. J. 1998. Estimating the economic impact of breeding nonspecific resistance to leaf rust in modern bread wheats. Plant Dis. 82:1055-1061.

Breeding for resistance to rust diseases in wheat is an example of productivity maintenance research. Productivity maintenance research is necessary to avoid contractions in the wheat supply curve that result from changes in the biological or physical environment. In this study, the benefits of incorporating nonspecific resistance to leaf rust caused by Puccinia recondita into modern bread wheats (Triticum aestivum) have been estimated using data on resistance genes identified in cultivars, trial data, and area sown to cultivar in the Yaqui Valley, Sonora State, Mexico. In the most pessimistic scenario, the gross benefits generated in the Yaqui Valley from 1970 to 1990 were 17 million U.S. dollars (in 1994 real terms). Even when costs were overstated and benefits were understated, the internal rate of return on capital invested was $13 \%$, well within the range recommended for use in project evaluations by the World Bank. Substantial economic benefits likely are associated with deployment of nonspecific resistance in many wheat-producing areas of developing countries where farmers change cultivars slowly because of delays in cultivar release, incomplete seed markets, and economic factors related to adoption or where disease pressure is heavy and the costs of treating disease outbreaks is high.
\end{abstract}

Additional keywords: disease loss

Breeding for resistance to rust disease in wheat is an example of productivity maintenance research. Unlike research that enhances productivity by increasing crop output for a specified quantity of input, maintenance research counteracts crop losses that result from changes in the biological or physical environment. Productivity enhancement is measured in terms of positive yield gains associated with research investment; productivity maintenance must be estimated in terms of the yield losses that would have occurred in the absence of the research investment. The two types of research are conceptually distinct, but estimating their separate contributions to crop yields in farm fields is difficult.

Although researchers have long argued that productivity maintenance research is important (19), there are relatively few economic analyses of this type of research, particularly on breeding for disease resistance $(2,6,11,15,20)$. Research at the Inter-

Corresponding author: M. Smale

E-mail: msmale@cimmyt.mx

Accepted for publication 11 June 1998.

Publication no. D-1998-0717-01S

(C) 1998 The American Phytopathological Society national Maize and Wheat Improvement Center (CIMMYT), Mexico, D.F., indicates that over the past few decades the impact of breeding for genetic resistance has generated a large proportion of the global economic return to investment in international wheat research (4). Recent analysis of trials conducted in the Yaqui Valley, Sonora State, Mexico, confirms that progress in protecting yield potential through genetic resistance to leaf rust caused by Puccinia recondita Roberge ex Desmaz. f. sp. tritici Eriks \& E. Henn.) has been approximately three times as great as advances in yield potential (24).

Genetic resistance, rather than use of fungicides, remains the principal means of controlling wheat rusts. This is especially true in wheat-producing areas of developing countries, where the costs of controlling disease outbreaks are relatively high. Wheat breeders have known for some time that race-specific resistance in diseases such as rusts contributes to a "boom-bust" cycle of resistance and associated genetic vulnerability because of shifts in the pathogen population (22).

For this reason, utilization of nonspecific resistance, as defined theoretically by Vanderplank (27) and applied to leaf rust resistance by Caldwell (5), has been the dominant selection method used during the past 25 years by CIMMYT's wheat-breeding program (21). Genes conferring racespecific resistance tend to produce resistant reactions, but their effects are overcome in a relatively short period of time. In contrast, genes conferring race-nonspecific resistance to leaf rust in wheat have partial and additive effects, and although the response to infection is essentially susceptible, the rate of disease progress is slowed (22). Geneticists and pathologists at CIMMYT now believe that adequate levels of nonspecific resistance can limit disease losses to insignificant levels in farm fields (22). Further, nonspecific resistance is more likely to endure for many cropping seasons.

The objective of our study was to estimate the economic benefits of CIMMYT's decision to incorporate nonspecific rather than specific resistance to leaf rust into its bread wheats. This case study, based on data from the irrigated Yaqui Valley in northwestern Mexico, is an application of basic economic analysis to a type of productivity maintenance research.

\section{MATERIALS AND METHODS}

General approach. Before providing details on the methods and materials used, we need to explain the underlying concepts on which the analysis is based and which distinguish it from conventional impact studies. The principal challenge in estimating the benefits of research on genetic resistance to rusts is the simple fact that rusts evolve: resistance conferred by any given gene or gene combination usually is temporary. The longevity of any new source of resistance is unknown when a cultivar carrying it is released. If detailed, historical, farm-level data were available on annual losses from rust over extensive areas of wheat production, estimating the benefits would consist only of tabulation. Without these data, benefits must be estimated based on expected losses and predictions of the longevity of resistance as they relate to the diffusion paths of the cultivars carrying each type of resistance. The diffusion path of the cultivar is its adoption rate, or the percent area farmers plant to it, measured over time.

Our approach was to estimate the benefits of nonspecific resistance as the value of the yield losses that would have occurred in the study area if a strategy for specific resistance, rather than nonspecific 
resistance, had been employed. The magnitude of yield savings associated with nonspecific resistance is based on the differences in yield losses that occur between the two types of resistance as a function of the field life of the cultivar. With specific resistance, yield losses from disease are assumed to be negligible until the pathogen evolves to overcome the resistance. When this occurs, yield losses usually are large. With nonspecific resistance based on partially effective genes, slight yield losses from disease may occur in some years immediately following a cultivar's release. However, the path of deterioration in resistance, if it occurs, is more gradual and may not cause large losses for many years.

The longevity of resistance varies by cultivar and the environment in which it is grown, including crop management practices, spatial distribution of cultivars, other crops in the farming system, and weather patterns. All of these factors can affect the occurrence or increase in the frequency of a virulent race. In Kilpatrick's (14) survey of wheat-producing countries, for example, the estimated average frequency of race changes in rusts was $\approx 5$ years, although few data points were reported.

The benefits associated with growing a cultivar with nonspecific resistance occur only when a farmer grows wheat cultivars for a longer period than specific resistance would be effective. Farmers may replace wheat cultivars infrequently because of their own preferences for yield, other agronomic characteristics, or characteristics of the seed

Table 1. Effects of genetic resistance on grain yield losses due to leaf rust in Mexican wheat cultivars derived from the International Maize and Wheat Improvement Center germ plasma

\begin{tabular}{lcl}
\hline $\begin{array}{l}\text { Explanatory } \\
\text { variable }^{\mathbf{b}}\end{array}$ & $\begin{array}{c}\text { Regression } \\
\text { Coefficient }^{\mathbf{c}}\end{array}$ & SE \\
\hline Constant & -7.76 & \\
Dummy $^{\mathrm{d}}$ & -5.18 & 2.95 \\
Dummy $^{\mathrm{e}}$ & -1.43 & 1.86 \\
Dummy $^{\mathrm{f}}$ & 4.47 & 2.33 \\
Dummy & $-15.9^{*}$ & 4.29 \\
Days to anthesis & $0.778^{*}$ & 0.207 \\
Days to maturity & 0.105 & 0.196 \\
Age of cultivar in 1996 & $0.609^{*}$ & 0.122 \\
Presence of $L r 16$ & & \\
$\quad$ complex & $-51.0^{*}$ & 3.16 \\
Presence of $L r 19$ gene & $-50.8^{*}$ & 3.33 \\
Presence of $L r 34$ & & \\
$\quad$ complex & $-47.9^{*}$ & 2.39 \\
No. of other nonspecific & & \\
$\quad$ genes & $-30.14^{*}$ & 3.86 \\
No. of other nonspecific & & \\
$\quad$ genes (squared) & $4.73^{*}$ & 1.64 \\
$R^{2}$ & 0.73 & \\
\hline
\end{tabular}

a Sayre et al. (24), trial data $(N=270)$, Yaqui Valley, Mexico.

${ }^{b}$ The dependent variable is the percentage of yield lost to leaf rust disease.

$\mathrm{c} *$ indicates result is statistically significant at 0.01 based on a one-tailed $t$ test.

d 1 if trial year is 1991,0 otherwise.

e 1 if trial year is 1992, 0 otherwise.

f 1 if trial year is 1993, 0 otherwise.

$\mathrm{g} 1$ for normal planting date, 0 if planted late. system that constrain their choices, such as low rates of cultivar release or slow dissemination of new cultivars. Patterns of cultivar turnover have been reported for the developed and developing world by Brennan and Byerlee (1), and the determinants of cultivar replacement have been analyzed by Heisey and Brennan (12). For many regions of the developing world, the average age of wheat cultivars, weighted by the area planted to them, is more than 10 years (26).

The methods and materials used in each of the four analysis steps are described below. Step 1 is the estimation of the yield effects of specific and nonspecific resistance to leaf rust. Step 2 is the prediction of the longevity of resistance to leaf rust for specific and nonspecific resistance. Step 3 is the simulation and sensitivity analysis for the net benefits from the investment. Step 4 is the computation of the internal rate of return on research investment. Steps 1 and 2 require some conceptual development because of the nature of benefits streams associated with maintenance breeding for genetic resistance to disease. A benefits stream is the magnitude of benefits measured over time. Steps 3 and 4 involve the application of standard approaches used in analyzing economic returns to investment, based on the conceptual development and estimates from the preceding steps.

Step 1: Yield effects of specific and nonspecific resistance to leaf rust. In the first step, regression analysis was used to estimate the effects on disease losses of nonspecific gene complexes and specific genes, using knowledge of the genetic basis of resistance and experimental data. The data are from an experiment conducted and analyzed by Sayre et al. (24), in which 15 CIMMYT-derived bread wheats released by the Instituto Nacional de Investigaciones Forestales, Agrícolas y Pecuarias, Mexico, from 1966 to 1988 were grown under farmers' management conditions for four seasons in the Yaqui Valley, with and without fungicide. The level of inoculation with rust pathogens was the same for all cultivars across the four seasons.

The regression analysis reported on in Table 1 shows the estimated effects of genetic resistance type on yield losses due to leaf rust. The dependent variable in the regression is the yield difference between protected and unprotected plots, as a percentage of the protected yield. Unlike conventional yield loss functions, in which yield or yield losses are related to variation in disease severity, in this regression the explanatory variables are genes conferring resistance, variables controlling for crop management and environment, and age of genotype. Control variables include dummy variables for the year of the experiment, planting date, days to anthesis, and days to maturity. The estimated coefficients represent the effects of particular genes, gene complexes, and age of cultivar on percentage of yield lost due to rust infection, con- trolling for management and seasonal factors.

All of the 15 bread wheats used by Sayre et al. (24) were resistant to leaf rust when released, but all resistance based on specific genes, except that of $L r 19$, has since been overcome. $\operatorname{Lr} 19$, a specific gene, is still effective in the Yaqui Valley. The Lr16 complex includes a specific gene (Lrl6) and at least two other partially effective genes. Alone Lr16 confers only moderate resistance; its resistance increases additively in the presence of the other genes in the complex. In Mexico, the Lrl6 complex has behaved similarly to nonspecific resistance genes (25). The Lr34 complex includes Lr34, which although named has a partial effect, as well as other unnamed nonspecific genes (22). Cultivars containing the Lr34 complex usually show less than $20 \%$ leaf rust severity at maturity under heavy rust pressure (22). The variable other nonspecific genes refers to the number of unnamed, nonspecific genes not included in the complexes described above. Although the cultivars carrying such resistance demonstrate slow progress in rust infection during the cropping season, final disease severities are intermediate to high (24).

No more than one of these genetic resistance types is found in any of the cultivars included in the experiment. The presence in a cultivar of any one of them-the effective specific gene $\operatorname{Lr19}$, the $L r 16$ complex, or the Lr34 complex-generates an average yield savings in infected plants of $\approx 50 \%$ (Table 1). These results imply that if challenged with the same disease pressure the use of either an effective specific gene or the described gene complexes is essentially the same during that season. In farm fields, there is variation in disease pressure caused by management and environmental factors. The individual effects of other nonspecific genes are not as great (an average of 30\% yield savings) and, as suggested by the estimated coefficient of the quadratic term, the individual effects decrease with each additional gene.

The age variable captures the residual yield differences that remain unexplained once the known genetic improvements have been considered. There are two possible explanations for its effect, in addition to increased genetic yield potential. The first is that not all genetic improvements in resistance have been measured in the specified variables. A second explanation relates to the observation that the yields of older materials are lower when planted in today's soils than at the time of their release. If the decline reflects deteriorating soil structure, then breeders selecting successively higher yielding materials have unwittingly selected for greater nutrient use efficiency (24). Such selection would constitute an additional improvement in productivity maintenance compared to genetic potential.

Step 2: Predicted longevity of resistance to leaf rust. The regression coeffi- 
cients reported in Table 1 provide an estimate of the difference in yield losses from rust disease between bread wheats with nonspecific resistance and specific resistance once specific genes are no longer effective and under conditions of heavy disease pressure. Combined with the known or predicted longevity of specific resistance, they can be used as an upper bound in estimating the level of resistance over time and the annual benefits associated with use of nonspecific resistance.

In the second part of the analysis, the longevity of resistance for cultivars in the Yaqui Valley was predicted by data on actual longevity and a simple actuarial computation. For each of the 38 bread wheats grown by farmers on more than $1 \%$ of the area in the Yaqui Valley from 1968 to 1996 , resistance genes were identified. These cultivars include, but are not limited to, those grown in the trials reported above. They were grouped into five broad categories based on their leaf rust severity ratings, as observed during the 4-year period of the trial. Resistance categories R (resistant), MR (moderately resistant), and MR-MS (moderately resistant to moderately susceptible) were considered effective, whereas susceptible categories MS (moderately susceptible) and S (susceptible) were considered ineffective. Resistance was defined as effective as long as the cultivar maintained useful levels of resistance in most years, showing more infection when disease pressure was heavy but not succumbing. The definition is appropriate for use in this study, because farmers often continue to grow cultivars with MR-MS resistance even though wheat breeders may no longer consider it satisfactory.

Parametric approaches such as duration models can be employed to relate genetic factors to longevity of resistance through

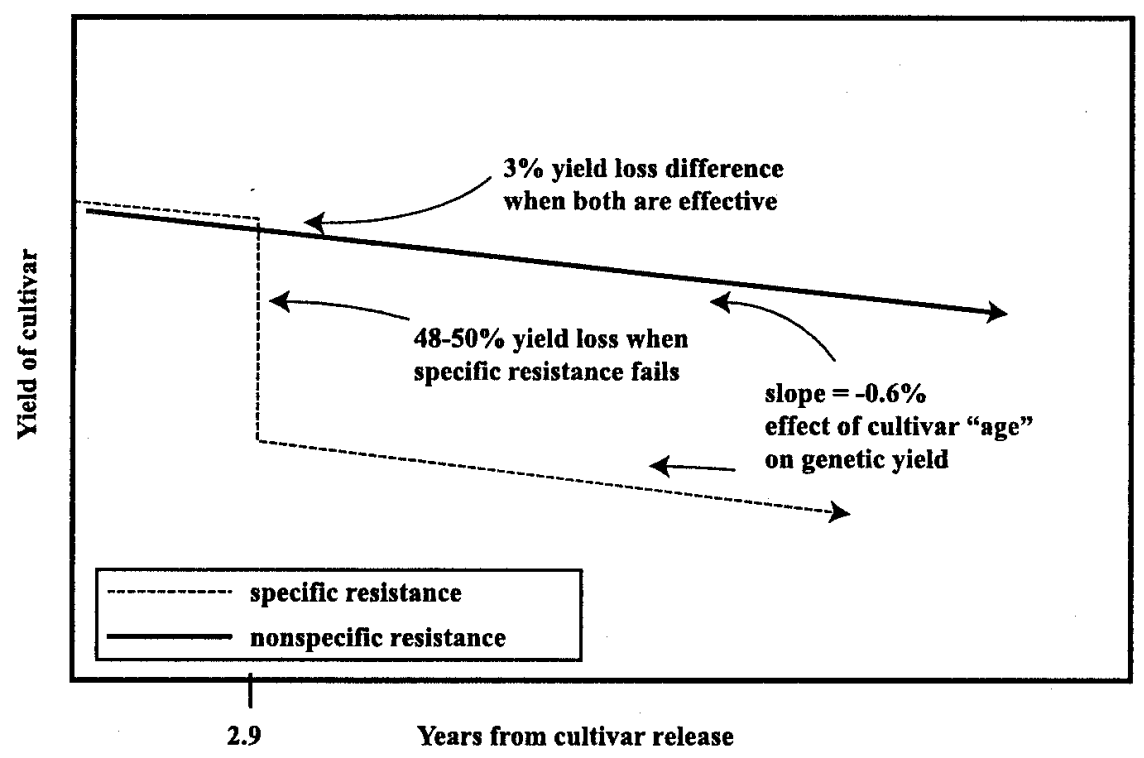

Fig. 1. Conceptual representation of yield paths when resistance to leaf rust is overcome in bread wheats, Yaqui Valley, Mexico (percents refer to estimates in Table 1). regression analysis but cannot be estimated unless resistance has been overcome for at least some cultivars in each resistance class $(10,13)$. In our data, none of the cultivars carrying nonspecific resistance had become susceptible. We used nonparametric analysis of frequency distributions for cultivars whose resistance had been overcome and those for which resistance was still effective to make actuarial predictions of longevity of rust resistance among cultivars grown in the Yaqui Valley (10). The exculated as the cumulative proportion of cultivars whose resistance had not been overcome by the beginning of the time interval, uniformly factoring in the effects of unobserved duration times. The analysis gave the conditional probability that a cultivar's resistance would be overcome, given that it had not yet been overcome. This method provides estimates of longevity that can be compared statistically between types of genetic resistance. It also can be used when longevity of resistance is known only for a sample of cultivars.

The analysis demonstrated that by the end of the third year after release in the Yaqui Valley there is a $70 \%$ cumulative probability that resistance to leaf rust will have failed among all cultivars that do not contain nonspecific resistance. The expected lifetime of specific resistance to leaf rust in a cultivar is only 2.9 years. The null hypothesis that the frequency distributions for longevity of resistance are the same was rejected because none of the cultivars with nonspecific resistance had lost their resistance. The relationships estimated from the data suggest time paths of yield loss for specific and nonspecific resistance as depicted in Figure 1. Figure 1 is a conceptual figure that provides the basis of the estimation of benefits in step 3. The estimated pected longevity of rust resistance was cal- regression coefficients in Table 1 were used to derive the shape of the time paths for the two types of resistance.

Step 3: Method used to simulate benefit streams. Initially, an attempt was made to estimate the effect of nonspecific resistance genes on farm-level wheat yields through estimation of a production function with regression analysis of survey data (8). The attempt was unsuccessful because in the farm-level data gene effects were masked by variation in environment and management practices that could not be controlled in the type of statistical model specified. The finding does make sense; to estimate a plausible regression model would require data from a trial designed specifically to mimic farm conditions and epidemiological patterns over time. A simulation analysis for the benefit streams, therefore, was conducted as the third step in the analysis, using parameters estimated in the first two steps as a starting point, combined with data on area distributions for cultivars grown in the Yaqui Valley, yields, and prices. The magnitudes of the parameters were varied to demonstrate the sensitivity of results to underlying assumptions about their magnitude.

If actual disease losses over the study time period were known, the calculation of benefits in terms of yield losses avoided would be straightforward. In year $t, m$ wheat cultivars, $i=1, \ldots, m$, are grown by farmers, of which $n \leq m$ carry specific resistance and the remainder carry nonspecific resistance to leaf rust. Cultivar $j$, with nonspecific resistance, maintains its disease-resistant yield of $y_{j t}$ throughout the years that farmers choose to grow it or its field life. Cultivar $i$, with specific resistance, has a disease-resistant yield of $y_{i t}$ until $t=d_{i}$, the year when its resistance is overcome. This year is specific to each cultivar. From this year until the end of its field life in year $t=K_{i}$ (for the period $d_{i}<$ $\left.t \leq K_{i}\right)$, it is highly susceptible to disease loss and its yield is only $y_{i t}{ }^{*}=\left(1-\gamma_{i t}\right) y_{i t}$, where $\gamma_{i t}$ is the percent yield loss for the cultivar in year $t$. The output losses from the cultivation of cultivars with specific resistance over the time period under study is

$$
Q=\sum_{t=1}^{T} \sum_{i=1}^{n} \gamma_{i t} y_{i t} a_{i t}^{*}
$$

where $\gamma_{i t}>0$ for $d_{i}<t \leq K_{i}$ and $\gamma_{i t}=0$ otherwise.

Output losses for each cultivar are the product of the percentage of resistant yield lost due to disease, resistant yield, and area planted to the cultivar in each year after resistance has been overcome. $Q$, the total output loss, is the sum of annual yield losses due to rust for cultivars with specific resistance, after resistance has been overcome and while farmers still grow the cultivars, summed over the years. These output losses, when valued, are the costs of planting cultivars with specific rather than nonspecific resistance; conversely, they are 
the benefits of nonspecific resistance in terms of losses avoided.

When, as in this study, actual losses are unknown, the key parameters in determining the magnitude of expected benefits are (i) the disease losses for susceptible cultivars in any year $\left(\gamma_{i t}\right)$; (ii) the yield level of cultivars with specific resistance $\left(y_{i t}\right)$; (iii) the length of the period from the year when resistance is overcome to the year when farmers cease to grow the cultivar $\left(K_{i}-d_{i}\right)$; (iv) the extent of the area planted to susceptible cultivars $\left(a_{i t}{ }^{*}\right)$; (v) the deflated (real) price of wheat; and (vi) the interest rate used to represent the time value of money in the benefits stream. Each of the fol- lowing factors has a positive effect on the expected cost of specific resistance or the expected benefits of nonspecific resistance: (i) the percent disease loss for a given yield level; (ii) the level of the resistant yield; (iii) the extent of the area planted to cultivars after their resistance has been overcome; and (iv) the length of the time period in which the cultivars remain in cultivation after resistance has been overcome.

In simulating the benefits stream for nonspecific resistance, the parameter values shown in Table 2 were combined with actual area, yield, and price information for bread wheats in the Yaqui Valley from 1970 to 1990 . Because farm-level yield esti-

Table 2. Estimated gross benefits of nonspecific versus specific resistance to leaf rust in Mexican wheat cultivars derived from the International Maize and Wheat Improvement Center germ plasm, Yaqui Valley, Mexico, 1970 to 1990

\begin{tabular}{|c|c|c|c|c|}
\hline Parameter $^{\mathrm{a}}$ & Benefits $^{\mathbf{b}}(\$)$ & $\begin{array}{c}\text { Average } \% \text { of total } \\
\text { value of annual } \\
\text { wheat production }\end{array}$ & $\begin{array}{l}\text { Change in benefits } \\
\text { from base }(\$)^{d}\end{array}$ & $\begin{array}{c}\% \text { Change in } \\
\text { benefits from base }\end{array}$ \\
\hline $\begin{array}{l}\text { Base } \\
\qquad \begin{array}{l}\gamma=9 \\
r=10 \\
a^{*}=35 \\
d_{i}(\text { varies, mean }=3) \\
K_{i}(\text { varies, mean }=5)\end{array}\end{array}$ & 16.90 & 0.547 & & \\
\hline \multicolumn{5}{|l|}{ Sensitivity } \\
\hline$\gamma=19$ & 35.60 & 1.16 & 19 & 111 \\
\hline$\gamma=39$ & 73.10 & 2.37 & 56 & 333 \\
\hline$\gamma=49$ & 91.90 & 2.98 & 75 & 444 \\
\hline$r=1$ & 39.50 & 1.28 & 23 & 134 \\
\hline$r=15$ & 11.70 & 0.38 & -5 & -30.9 \\
\hline$a^{*}=36$ & 26.60 & 0.86 & 10 & 58 \\
\hline$a^{*}=40$ & 62.40 & 2.02 & 46 & 270 \\
\hline$d_{i}=4$ & 14.60 & 0.47 & -2 & -13.7 \\
\hline$K_{i}^{\mathrm{d}}(\operatorname{mean}=5)$ & 24.10 & 0.78 & 7 & 42.8 \\
\hline
\end{tabular}

${ }^{\mathrm{a}} \gamma$ is the average percent yield loss due to leaf rust; $r$ is the interest rate; $a^{*}$ is the percentage of bread wheat area in cultivars with specific resistance that is no longer effective, averaged over 1970 to 1990; $d_{i}$ is the number of years from release until resistance is no longer effective; $K_{i}$ is the field life of the cultivar. Both $d_{i}$ and $K_{i}$ vary by cultivar.

b Total benefits (in millions) calculated in 1994 U.S. dollars.

c Percentage of total value of wheat production in 1994 U.S. dollars at that year's exchange rate, using planted area and wheat yields of 5 tonnes/ha divided by 20 (for years).

${ }^{\mathrm{d}}$ Increased by 1 year for each cultivar, at the percentage of area of final recorded year.

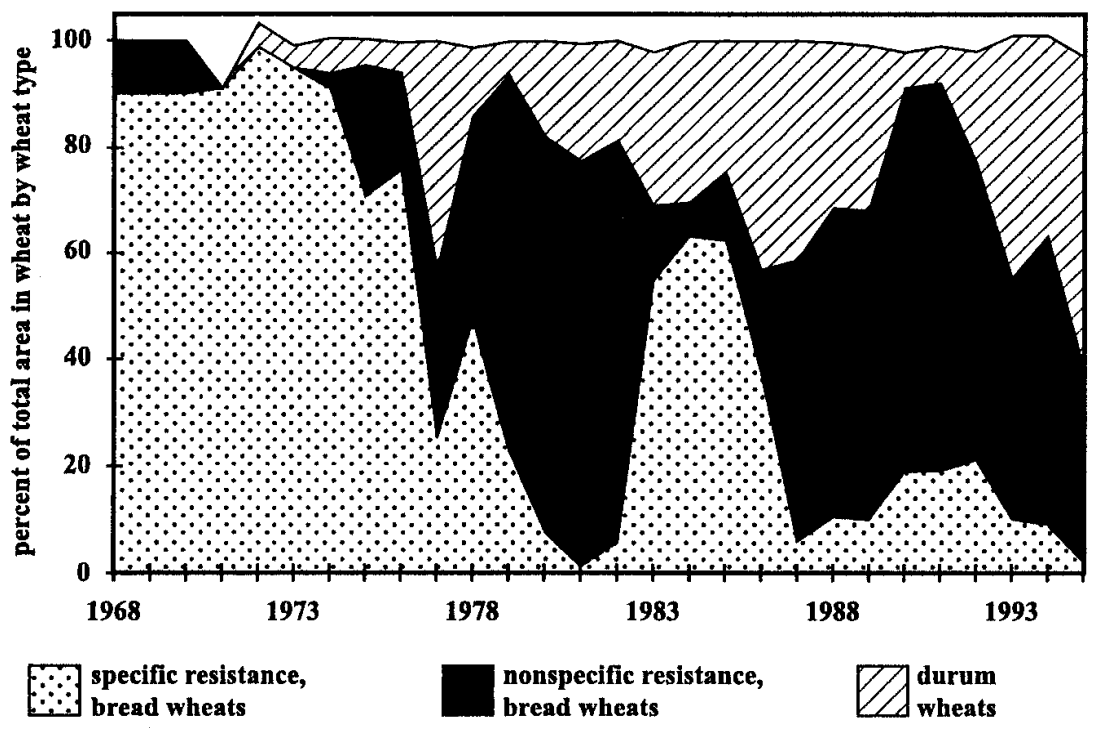

Fig. 2. Percent wheat area by wheat type and type of rust resistance, Yaqui Valley, Mexico, 1968 to 1995.

mates were not available by cultivar, resistant yields were calculated algebraically from the average yield data for all wheats grown in the Yaqui Valley, given an average yield differential of 0.42 tonnes/ha between durum and bread wheats (8). Longevity of resistance and field life were known for each of the cultivars. The parameter used for area represents the hectares actually planted to cultivars with nonspecific resistance that would have been planted to susceptible cultivars with specific resistance had the research investment in nonspecific resistance not been made. We assumed the proportion to be the same as the actual proportion of area in susceptible cultivars with specific resistance.

The total areas planted to cultivars with specific and nonspecific resistance are shown in Figure 2. In the Yaqui Valley, since 1990 economic factors unrelated to resistance may have contributed to a rising average age and area-weighted average age of bread wheats grown by farmers. For cultivars with specific resistance, this implies a longer period from $d_{i}$ to $K_{i}$. However, bread wheats with specific resistance occupy a generally decreasing percentage of the bread wheatproducing area in the Yaqui Valley. The percent fluctuates over time, reflecting the diffusion paths of cultivars. The resurgence in area planted to cultivars with specific resistance during the mid-1980s is associated with the diffusion of the high-yield, widely adapted wheat cv. Seri 82 from a cross involving spring and winter wheats.

The disease loss for any cultivar in any year $\left(\gamma_{i t}\right)$ is generally higher in zones of high disease pressure than in others and much higher during epidemic years when losses cannot be averted during the cropping season by means of chemical control. In the Yaqui Valley, actual disease losses $\left(\gamma_{i t}\right)$ in farm fields have not been measured. The trial data used to estimate the yield savings from the Lr16 and Lr34 complexes represent farmers' management practices fairly closely, although the disease pressures are heavier in the experiments than those now experienced by Yaqui Valley farmers during most years. In the absence of actual data on annual disease losses or weather conditions, management practices, and spatial distributions that would allow us to predict the extent of disease pressure from year to year, it is impossible to derive quantitative estimates of the $\gamma_{i t}$ time paths. The parameter estimate we have for the percent reduction in disease loss due to nonspecific resistance in cultivars that have been grown in the Yaqui Valley (based on the Lrl6 or Lr34 complex) is a constant, $\gamma$. We used the estimates from Table 1 and other figures reported in the literature $(7,16-18)$ to establish upper and lower bound for this parameter.

The benefits associated with avoiding output losses are the discounted value of the expected yield losses avoided in the Yaqui Valley from 1970 to 1990 by choos- 
ing to invest in nonspecific resistance. Discounting is a basic technique used in economic analysis of investment decisions to collapse a stream of future costs and benefits into one total value representing present worth (9). Present refers to the time at which the decision is made. The technique is used to express the notion that a given amount of money in hand today is of higher value than the same amount earned in the future. The interest rate, also termed the discount rate, represents the value that decision-makers place on earnings received today compared to those received tomorrow. The general formula for calculating discounted benefits for an investment is

$$
\text { Present value }=\sum_{t=1}^{n} \frac{B_{t}}{(1+r)^{t}}
$$

$B_{t}$ is the benefit in each time period of the $n$ years over which they are earned, and $r$ is the interest rate (9). When costs are subtracted from benefits in each time period, equation 2 is termed the net present worth and is one of several measures used to calculate the value of an investment. A complete description of methods used to evaluate the worth of an investment is provided by Gittinger (9) and can be found in other standard economics texts.

In this study, using discounted benefits as a measure of the worth of the investment reflects the fact that we are viewing the investment decision from the beginning of the time period (1970), as did the decision-makers in CIMMYT's wheat-breeding program when they changed their strategies for incorporating resistance to leaf rust. We used the deflated rural price of wheat in new pesos (base year $=1994)$ to account for the effects of inflation on the value of benefits generated in each year. For the sensitivity analysis presented in Table 2, the sum of discounted benefits was converted to U.S. dollars at the average 1994 exchange rate.

Step 4. Internal rate of return. In the final step, with the addition of cost information for the pathology program at CIMMYT, an analysis of the internal rate of return on research investment was conducted. The internal rate of return, which is related to equation 2, is the interest rate, $r$, that equates the sum of discounted benefits to the sum of discounted costs:

$$
\sum_{t=1}^{n} \frac{B_{t}-C_{t}}{(1+r)^{t}}=0
$$

The most common means of computing the internal rate of return is to subtract costs from benefits year-by-year to obtain the net benefits stream, discount the stream, and solve for the $r$ that satisfies equation 3 by trial and error. Figure 3 depicts the results of this exercise, using different assumptions about disease loss and length of research lag. The research lag is the time period from the initiation of research to the release of resistant germ plasm.
The cost was assumed to be roughly equivalent to the salaries and operating expenses of a full-time wheat breeder and a full-time pathologist or a deflated cost of \$0.5 million per year, beginning in 1968 . Because the scientists in the pathology program are integrated into a crop-breeding program that provides a range of functions and activities other than pathology, the fixed costs of the buildings and station have not been included. Although the benefits streams record the difference between the benefits with the two types of resistance, the cost stream represents the full cost of running the pathology program at CIMMYT headquarters. There are two interpretations for this assumption. First, although the work of the pathology program at CIMMYT was targeted to nonspecific resistance, materials with specific resistance that were discovered in this process were not discarded; specific resistance was a joint product of the search for nonspecific resistance. A second way to interpret the assumption is that it overstates the cost of the strategy for nonspecific resistance, because the strategy provides other research benefits. By overstating the cost of the strategy, net benefits are understated.

Several alternative rate of return analyses were conducted, with benefits streams beginning after research lags of 5 years (with the release of cv. Torim 73) and 10 years. Five years is typically used for studies of CIMMYT materials, whereas ten years may be more appropriate for national programs. Time is critical to the calculation of the internal rate of return, and the longer the research lag, the lower the internal rate of return, when the other factors in the analysis are held constant.

\section{RESULTS}

Base scenario. As conceptualized in this paper, the estimated gross benefits of nonspecific resistance to leaf rust in bread wheats represent the value of the expected yield losses avoided by selecting for nonspecific resistance (Table 1; Fig. 1). The base scenario uses the calculated area distributions and yields, with a very conservative estimate of $\gamma=0.09$ and $r=10 \%$. With these conservative assumptions, the worth in 1970 of the future benefits generated in the Yaqui Valley alone during the 1970 to 1990 period was \$17 million (in 1994 U.S. dollars). As a point of reference, this amount represents, when annualized over the 1970 to 1990 period, about $0.6 \%$ per year of the 1994 value of wheat production in the Yaqui Valley (Table 2).

The values in Table 2 indicate the benefits for the base scenario and how the benefits change with changes in assumptions about parameter values. They can be interpreted as the incremental effects of changes in one parameter value on benefits when other parameter values are held constant. This type of analysis, sensitivity analysis, is a simple, straightforward tool for treating uncertainty in economic analysis of projects and is used to test what would have happened if events differed from the assumptions made about them.

A small change of $1 \%$ in the area planted to susceptible cultivars increases benefits by $58 \%$. Estimated benefits in the baseline scenario were calculated with the actual longevity of resistance and lifetimes of cultivars grown in farm fields in the Yaqui Valley. The area planted to bread wheats with specific resistance that had been overcome averaged $35 \%$ of the total area $\left(a_{t}{ }^{*}\right)$ each year during the 1970 to 1990 period. This concentration of area in susceptible cultivars is likely to be considerably lower than in many wheat-producing regions of the developing world.

Increasing the time of effective specific resistance by 1 year among cultivars grown in the Yaqui Valley decreases the benefits by $14 \%$. Over the time period, the area planted to susceptible cultivars is a function of both the longevity of their

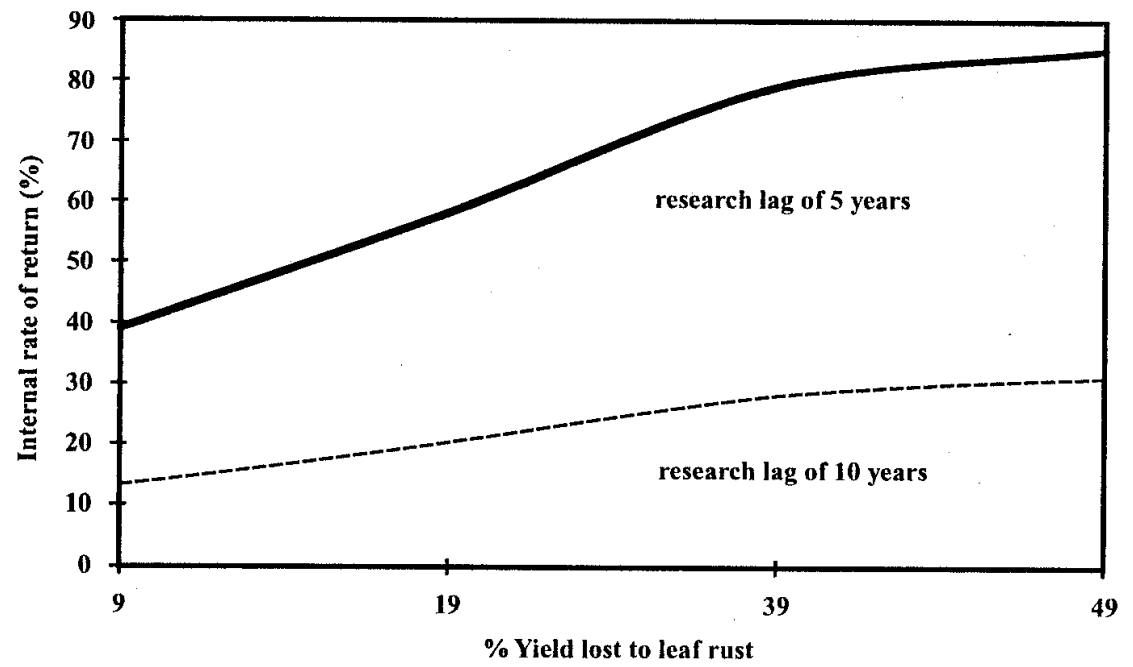

Fig. 3. Internal rate of return to research investment in nonspecific versus specific resistance to leaf rust in bread wheats, Yaqui Valley, Mexico. 
resistance $\left(d_{i}\right)$ and their lifetime in cultivation $\left(K_{i}\right)$. Although heavy disease pressures in the Yaqui Valley lead to a relatively brief time until resistance is overcome $\left(d_{i}=3\right.$ when averaged over the $i$ cultivars), farmers also change their bread wheats rapidly, and the average field life of a cultivar is only 5 years. When the lifetime in cultivation for susceptible bread wheats is expanded by 1 year at the percent area recorded for their final year in actual cultivation, benefits are $43 \%$ higher (Table 2). The key time period for the size of benefits is the span $\left(K_{i}-d_{i}\right)$-only 2 years on average in the Yaqui Valley during the study period. This period of time is brief compared to other wheat-producing areas in developing countries, where the turnover of cultivars is slower $(1,26)$.

Benefit results are very sensitive to assumptions about average disease losses. The disease loss parameter used in the baseline scenario was reduced from that estimated in the analysis of trial data to represent lower disease pressure in farm fields during most years. During the time period under study, yield losses of more than $40 \%$ occurred only in 1977 (7), although they occurred more frequently and with great severity during the 1930 s and 1940 s for stem rust. In 1977, losses were averted by a massive, well-organized campaign of chemical control. With the ceiling value of the disease loss parameter (49\%), losses were $\$ 92$ million (in 1994 dollars) (Table 2).

Using a social discount rate of $1 \%$, compared to an opportunity cost of capital of $10 \%$, increases benefits by $134 \%$. Which level of $r$ is appropriate to use in an economic analysis is the subject of extensive debate in both the applied and theoretical economics literature. The debate centers on which concept of the value of capital to use. For example, if $r$ is the opportunity cost of capital in an economy, it represents the return on the marginal investment that uses the last of the available capital. This $r$ is meant to reflect "the choice made by the society as a whole between present and future returns, and, hence, the amount of total income the society is willing to save" (9). For developing countries, a range of 8 to $15 \%$ in real terms often is assumed. Applying a $15 \%$ rate in this example causes a fairly large reduction in estimated gross benefits.

Another possible $r$ is the social time preference rate, which reflects the idea that society has a longer time horizon than individuals, and implies that a lower $r$ should be used for public projects than for private projects. CIMMYT, for example, is a publicly funded institution. In Table 2, the social time preference rate is represented by $r=1 \%$.

Gross benefits associated with the conservative base scenario are modest but sufficient to generate substantial rates of return on capital investment. Even with heavy cost penalties during the earlier years, a lag of 10 years in research benefits, and the most conservative assumptions regarding losses due to rust disease, the rate of return on capital is $13 \%$ ( $\$ 1.13$ on each $\$ 1.00$ invested)—-well within the range recommended for use as the opportunity cost of capital in project evaluations by the World Bank. A research lag of 5 years, which is more appropriate for this study, combined with the most conservative assumptions regarding disease, generates an internal rate of return of nearly $40 \%$ on benefits earned in the Yaqui Valley alone (Fig. 3).

\section{DISCUSSION}

The results presented here indicate that the economic benefits of breeding for nonspecific resistance to leaf rust in bread wheats have been substantial. Using the most conservative of assumptions regarding the values of the parameters, the expected gross benefits generated in the Yaqui Valley alone during the 1970 to 1990 period were \$17 million (in 1994 U.S. dollars). Although the estimated benefits for the Yaqui Valley are sensitive to the values of underlying parameters, they remain large enough that even when very pessimistic cost and benefit assumptions are used, the internal rate of return to capital is high enough to satisfy stringent investment criteria.

Several improvements in method might be considered in future economic analyses of this type. First, a variable disease loss parameter would be more realistic than a constant. Epidemiological models could be used to more accurately estimate variation in disease losses over time. Second, other methods of modeling spatial aspects of disease pressure might be investigated. Percent distributions of area across cultivars represent a very imperfect measure of spatial distribution (e.g., for example, they ignore the "mosaic effect," which explains why susceptible cultivars remain healthy when they are surrounded by resistant cultivars). Third, a parametric method could be used to relate genetic factors to longevity through multivariate regression analysis. Fourth, establishing a statistical relationship between yield losses in farm fields and genetic factors with a farm-level data set would provide important insights that are missing from simulation exercises.

Each of these refinements necessitates more data than are typically available to researchers, and greater precision in results and statistical confidence may not change the fundamental finding of the study. Assumptions used in simulation and sensitivity analyses, when properly guided by knowledgeable sources and data, permit researchers to effectively set lower and upper bounds on their results.

The findings are more likely to provide a lower bound than a representative estimate of the global rate of return to investment in nonspecific resistance to leaf rust for CIMMYT's mandate area. In 1990, CIMMYT and CIMMYT-derived materials were grown on an estimated $73 \%$ of the area planted to spring bread wheats in the developing world (3). A recent survey of wheat breeders in developing countries indicates that among the types of materials used in crossing (including the breeders own advanced lines, advanced lines borrowed from other countries, wild relatives, and landraces), materials from CIMMYT International Nurseries are the most frequently crossed in pursuit of disease resistance goals (23). A large percentage of the bread wheats grown in the developing world in 1990 contained in their pedigrees the ancestral source of the Lr34 complex, and most of these had at least one parent or grandparent of CIMMYT origin (M. Smale, unpublished data).

A comparison of the magnitude of the parameters used in the analysis of the Yaqui Valley and those appropriate for other zones in CIMMYT's mandate area suggests that the global rate of return is probably higher than the rate of return estimated in this study. On the benefits side, the research investment in nonspecific resistance to leaf rust is most relevant on an estimated 45 to 50 million ha of wheat in developing countries, compared to the mere 150,000 ha included in this study. The total area in susceptible cultivars, which is a function of time periods as well as other factors related to seed markets and government policies, also is likely to be higher in other developing countries. The Yaqui Valley is the location of one of CIMMYT's major experiment stations, and its farm fields are some of the first testing grounds of CIMMYT wheats outside experiment stations. Although disease pressures are greater there than in many parts of the developing world, the speed of cultivar replacement curtails the time period over which the benefits accrue for each cultivar. On the other hand, for some production environments, longer research lags, lower disease pressures, and lower rates of adoption of cultivars with nonspecific resistance would reduce the magnitude of the benefits per unit of area below those calculated for the Yaqui Valley.

In augmenting the scale of analysis from the Yaqui Valley to CIMMYT's mandate area, costs are not likely to increase proportionally to benefits, however. Although the costs of the international testing network and the costs borne by national programs have been excluded in this analysis, the cost streams are overstated because they represent heavier investments during early years than was actually the case and because they include the full cost at CIMMYT headquarters of the rust research program. If incremental costs were calculated for nonspecific compared to specific resistance, the costs of breeding for specific resistance would likely be greater than those associated with nonspecific resistance. Assumng that new resistance genes are increasingly scarce, the cost of searching wheat 
materials for them rises over time. Once the frequency of effective specific genes becomes low in advanced materials, other types of materials, such as landraces and wild relatives, must be searched. The cost of transferring resistance from these materials into advanced lines is higher. In the meantime, the research resources allocated to searching for and incorporating resistance are not spent in the pursuit of other important breeding objectives. Instead, pursuing nonspecific forms of resistance usually implies working within advanced lines for new, partially effective genes and gene complexes. New sources of partially effective resistance are accumulated in elite lines carrying known sources of resistance.

The calculations, however, did not include an important dimension of benefits from nonspecific resistance that is difficult to measure but important to recognize. Output losses from rust include both incremental, annual, and major losses incurred by epidemics. How socially important these losses are depends not only on their absolute magnitude, but the role of wheat production in the national economy, the attitude of the society toward risk, the time horizon, and other considerations influencing the valuation of the yield loss.

For some farmers and societies, the true costs of these losses-especially in epidemics-can be great because of the extent to which they rely on the wheat crop. Large crop losses may imply price increases that are passed to consumers or unforeseen imports purchased at world market prices that may not be favorable. Some farmers and societies, therefore, place added value on avoiding disasters. Modern epidemics may require treatment with fungicides and largescale, well-coordinated mobilization campaigns (7). Heavy chemical treatments may have secondary health costs. Nonspecific resistance effectively changes the yield distribution by reducing the probability of falling into the lower tail. By reducing the probability of disaster, it benefits farmers and societies that would find such outcomes disastrous.

Finally, the benefits of developing nonspecific resistance will extend into the future as resistant bread wheats are more widely adopted, although future benefits are worth less. Currently, the same strategy also is being applied to develop resistance to other diseases. Benefits from developing the strategy, therefore, will accrue by avoiding losses due to other diseases as well as to leaf rust.

Although the principal contribution of this study is its evidence of an economic return for nonspecific resistance, a secon- dary contribution may be its utility as a methodological tool for simple assessments of the economic rate of return on maintenance research. Although the economic analysis in steps 3 and 4 is basic, its application, in addition to the conceptual development in steps 1 and 2, represents the particular contribution of this study. Increased accuracy in rate of return studies is accomplished at greater cost but does not necessarily change policy implications. The policy implication of this study is that CIMMYT's strategy of pursuing nonspecific resistance to leaf rust has been well worth the investment.

\section{ACKNOWLEDGMENTS}

We thank P. Heisey, G. Traxler, R. Johnson, K. Leonard, E. Milus, M. van Ginkel, and four reviewers for comments and reviews. P. Aquino and D. Flores, Economics Program, CIMMYT, shared their knowledge of wheat production in the Yaqui Valley.

\section{LITERATURE CITED}

1. Brennan, J. P., and Byerlee, D. 1991. The rate of crop varietal replacement on farms: Measures and empirical results for wheat. Plant Var. \& Seeds 4:99-106.

2. Brennan, J. P., and Murray, G. M. 1989. Australian wheat diseases: Assessing their economic importance. Agric. Sci. 2:26-35.

3. Byerlee, D., and Moya, P. 1993. Impacts of International Wheat Breeding Research in the Developing World, 1966-90. International Maize and Wheat Improvement Center Mexico, D.F.

4. Byerlee, D., and Traxler, G. 1995. National and international wheat improvement research in the post-Green Revolution period: Evolution and impacts. Am. J. Agric. Econ. 77:268278.

5. Caldwell, R. M. 1968. Breeding for general and/or specific plant disease resistance. Pages 236-272 in: Proc. 3rd Int. Wheat Genet. Symp. K. W. Finlay and K. W. Shepherd, eds. Australian Academy of Sciences, Canberra.

6. Collins, M. 1995. The economics of productivity maintenance research: A case study of wheat leaf rust resistance breeding in Pakistan. Ph.D. thesis. University of Minnesota, St. Paul.

7. Dubin, H. J., and Torres, E. 1981. Causes and consequences of the 1976-77 wheat leaf rust epidemic in northwest Mexico. Annu. Rev. Phytopathol. 19:41-49.

8. Flores, D. V. 1997. Analysis of Yaqui Valley Wheat Production-On-Farm Diagnostic Study, 1981-1996. CIMMYT Internal Report. International Maize and Wheat Improvement Center, Mexico, D.F.

9. Gittinger, J. P. 1982. Economic Analysis of Agricultural Projects. 2nd ed. Johns Hopkins University Press, Baltimore.

10. Greene, W. H. 1992. Nonparametric analysis of duration data. LIMDEP User's Manual and Reference Guide. Version 6.0. Econometric Software, Inc., Bellport, NY.

11. Heim, M. N., and Blakeslee, L. 1986. Biological adaptation and research impacts on wheat yields in Washington. College of Agriculture and Home Economics, Washington State University, Pullman.
12. Heisey, P. W., and Brennan, J. P. 1991. An analytical model of farmers' demand for replacement seed. Am. J. Agric. Econ. 73:10441052.

13. Keifer, N. M. 1988. Economic duration data and hazard functions. J. Econ. Lit. 26:646-679.

14. Kilpatrick, R. A. 1975. New Wheat Cultivars and Longevity of Rust Resistance. ARS-NE-4. ARS-USDA, Beltsville, MD.

15. Morris, M. L., Dubin, H. J., and Pokhrel, T. 1994. Returns to wheat breeding research in Nepal. Agric. Econ. 10:269-282.

16. Nagarajan, S., and Joshi, L. M. 1985. Epidemiology in the Indian subcontinent. Pages 371-202 in: Diseases, Distribution, Epidemiology, and Control: The Cereal Rusts, Vol. 2. A. P. Roelfs and W. R. Bushnell eds., Academic Press, London.

17. Nagy, J. G. 1984. The Pakistan Agricultural Development Model: An Economic Evaluation of Agricultural Research and Expenditures. Ph.D. thesis. University of Minnesota, St. Paul.

18. Oerke, E.-C., Dehne, H.-W., Schonbeck, F., and Weber, A. 1994. Crop Production and Crop Protection: Estimated Losses in Major Food and Cash Crops. Elsevier Scientific Publishing, Amsterdam.

19. Plucknett, D. L., and Smith, N. J. H. 1986. Sustaining agricultural yields. Bio. Sci. 36:4045.

20. Priestley, R. H., and Bayles, R. A. 1988. The contribution and value of resistant cultivars to disease control in cereals. Pages 53-65 in Control of Plant Diseases: Costs and Benefits. B. B. Clifford and E. Lester, eds. Blackwell, Oxford.

21. Rajaram, S., Singh, R. P., and Torres, E. 1988. Current CIMMYT approaches to breeding for rust resistance. Pages 101-118 in: Breeding Strategies for Resistance to the Rusts of Wheat N. W. Simmonds and S. Rajaram, eds. International Maize and Wheat Improvement Center Mexico, D.F.

22. Rajaram, S., Singh, R. P., and van Ginkel, M. 1996. Approaches to breed wheat for wide adaptation, rust resistance and drought. Pages O2-O30 in: 8th Proc. Wheat Breeding Soc. Aust. R. A. Richards, C. W. Wrigley, H. M. Rawson, G. J. Rebetzke, J. L. Davidson, and R. I. S. Brettell, eds. Wheat Breeding Society of Australia, Tamworth, Australia.

23. Rejesus, R., Smale, M., and van Ginkel, M. 1997. Wheat breeders' perspectives on genetic diversity and germplasm use: findings from an international survey. Plant Var. \& Seeds 9:129-147.

24. Sayre, K. D., Singh, R. P., Huerta-Espino, J., and Rajaram, S. 1998. Genetic progress in reducing losses to leaf rust in CIMMYT-derived Mexican spring wheat cultivars. Crop Sci. 38:654-659.

25. Singh, R. P., and Huerta-Espino, J. 1995. Inheritance of seedling and adult plant resistance to leaf rust in wheat cultivars Ciano79 and Papago 96. Plant Dis. 79:35-38.

26. Smale, M. 1996. Understanding Global Trends in the Use of Wheat Diversity and International Flows of Wheat Genetic Resources. Economics Working Paper 96-02. International Maize and Wheat Improvement Center Mexico, D.F.

27. Vanderplank, J. E. 1963. Plant Diseases: Epidemics and Control. Academic Press, New York. 